\title{
CARACTERÍSTICAS MORFOFISIOLÓGICAS DE PLANTAS CLONAIS DE Passiflora alata CRESCIDAS EM DIFERENTES DOSES DE NITROGÊNIO E NÍVEIS DE SOMBREAMENTO ${ }^{1}$
}

\author{
JÔSIE CLOVIANE DE OLIVEIRA FREITAS², ALEX-ALAN FURTADO DE ALMEIDA, \\ MARIA FRAGASSI LAGO ${ }^{4}$, MARGARETE MAGALHÃES DE SOUZA \\ JOSÉ OLIMPIO DE SOUZA JÚNIOR ${ }^{6}$
}

RESUMO - Plantas clonais de Passiflora alata foram submetidas a quatro níveis de sombreamento (0; 25; 50 e 75\%) aos 75 dias após o estaqueamento (DAE). Dez dias após, aplicou-se nitrogênio (N) nas dosagens de 0; 25;50; 100 e $200 \mathrm{mg} \mathrm{N} \mathrm{kg}^{-1}$ de solo. Verificou-se, aos $175 \mathrm{DAE}$, interação significativa $(\mathrm{p}<0,05)$ entre níveis de sombreamento (NS) e doses de N, para todos os parâmetros fotossintéticos avaliados. Observou-

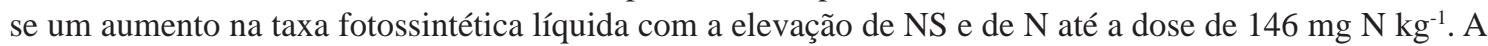
taxa transpiratória apresentou efeito quadrático tanto para NS quanto para N, tendendo a aumentar com o incremento de NS e $\mathrm{N}$ até $50 \%$ de sombreamento e $137 \mathrm{mg} \mathrm{N} \mathrm{kg}^{-1}$, respectivamente. A espessura dos tecidos do mesofilo foliar foi reduzida com a intensificação de NS. Os teores de clorofila $a, b$ e total aumentaram com a elevação de NS e N. Todos os parâmetros de crescimento analisados não apresentaram diferenças significativas $(\mathrm{p}<0,05)$ para a interação NSxN. O maior acúmulo de biomassa seca total foi obtido em $69 \%$ de sombreamento e na dose de $113 \mathrm{mg} \mathrm{N} \mathrm{kg}^{-1}$, ocorrendo um declínio nos NS nas e doses de $\mathrm{N}$ subsequentes. Em suma, os resultados demonstraram que o sombreamento moderado (50\%), associado a um suprimento moderado de $\mathrm{N}$, promoveu maior eficiência fotossintética e, consequentemente, incremento na biomassa seca, na planta toda.

Termos para indexação: crescimento; fotossíntese; maracujá-doce.

\section{MORPHOPHYSIOLOGICAL CHARACTERISTICS OF CLONAL PLANTS Passiflora alata GROWN IN DIFFERENT DOSES OF NITROGEN AND SHADING LEVELS}

\begin{abstract}
Passiflora alata clonal plants were submitted to four shading levels (0, 25, 50 and 75\%) at 75 days after cutting establishment (DAC). Ten days later, nitrogen (N) was applied at 0, 25, 50, 100 and $200 \mathrm{mg} \mathrm{N} \mathrm{kg}^{-1}$ of soil. A significant interaction $(\mathrm{p}<0.05)$ was observed between shading levels (SL) and $\mathrm{N}$ concentrations for all photosynthetic parameters evaluated at 175 DAC. There was an increase in the net photosynthetic rate with the increase of the SL and the $\mathrm{N}$, up to $146 \mathrm{mg} \mathrm{N} \mathrm{kg}^{-1}$ of soil. The transpiration rate showed a quadratic effect for both SL and N, increasing with the rise of SL and N, up to $50 \%$ shading and $137 \mathrm{mg} \mathrm{N} \mathrm{kg}^{-1}$, respectively. The leaf mesophyll thickness was reduced with SL intensification. The total chlorophyll and chlorophyll $a$ and $b$ content increased with the increase of SL and N. There were no significant differences $(\mathrm{p}<0.05)$ in the SLxN interaction, for all growth parameters analyzed. The higher accumulation of total dry biomass was obtained at $69 \%$ of shading and $113 \mathrm{mg} \mathrm{N} \mathrm{kg}^{-1}$, with decline in the highest SL and N levels. The results showed that a moderate shade (50\%) combined with an adequate $\mathrm{N}$ supply, increase the photosynthetic rate and biomass of the whole plant.
\end{abstract}

Index terms: growth, photosynthesis, sweet passion fruit.

\footnotetext{
${ }^{1}$ (Trabalho 038-12). Recebido em: 04-01-2012. Aceito para publicação em: 28-08-2012.

${ }^{2}$ Mestre em Produção Vegetal, Universidade Estadual de Santa Cruz (UESC). E-mail: cloviane_agro@hotmail.com

${ }^{3}$ Professor pleno do Departamento de Ciências Biológicas da UESC. E-mail: alexalan@uesc.br

${ }^{4}$ Estudante de Ciências Biológicas da UESC. E-mail: melfragassi@hotmail.com

${ }^{5}$ Professora Titular do Departamento de Ciências Biológicas da UESC. E-mail: souzamagg@yahoo.com.br

${ }^{6}$ Professor Titular do Departamento de Ciências Agrárias e Ambientais da UESC. E-mail: olimpio@uesc.br
} 


\section{INTRODUÇÃO}

O maracujá é uma fruta produzida em todos os Estados do Brasil, com exceção do Rio Grande do Sul e Roraima, sendo o Estado da Bahia o maior produtor, cuja produção foi de 322.755 toneladas em 2009. As principais espécies cultivadas comercialmente são Passiflora edulis f. flavicarpa Deg. e Passiflora alata Curtis, conhecidas popularmente como maracujá-azedo e maracujá-doce, respectivamente. Além do consumo in natura de seus frutos, a espécie $P$. alata é utilizada na indústria farmacêutica para produção de passiflorina (MELETTI; MAIA, 1999; FREITAS, 2006), e como planta ornamental, por possuir flores coloridas e perfumadas.

A irradiância e a nutrição mineral são dois fatores abióticos que afetam o crescimento e o desenvolvimento das plantas (HENRIQUES; MARCELIS, 2000). Dentre os nutrientes minerais, o N é de fundamental importância, uma vez que é requerido para a síntese de vários componentes celulares, a exemplo da molécula de clorofila e da Rubisco, um pigmento cloroplastídico importante e uma enzima responsável pela assimilação de $\mathrm{CO}_{2}$ durante as fases fotoquímica e bioquímica da fotossíntese, respectivamente (GONÇALVES, 2007). A demanda por $\mathrm{N}$ é determinada pela taxa de crescimento e pela sua composição na formação de novos tecidos, e o ganho de $\mathrm{CO}_{2}$ é incrementado pelo investimento em $\mathrm{N}$, dado que o aumento na disponibilidade de $\mathrm{N}$ resulta em maior expansão da parte aérea e, consequentemente, maior intercepção de luz (GRINDLAY, 1997). Além disso, a capacidade fotossintética em nível foliar está relacionada com os componentes da maquinaria fotossintética, cuja produção depende da disponibilidade de N (MOHOTTI; LAWLOR, 2002; GRASSI et al., 2002).

A deficiência de $\mathrm{N}$ diminui a capacidade das fontes e dos drenos metabólicos, reduzindo a formação dos componentes fotossintéticos e encurtando a vida média das folhas e o índice de área foliar (GONÇALVES, 2007; MOHOTTI; LAWLOR, 2002). Desta forma, a partição de biomassa seca entre raiz e parte aérea é controlada pela relação entre carbono (C) e N em plantas (GRECHI et al., 2007).

Além da disponibilidade de nutrientes minerais, a irradiância é outro fator abiótico que apresenta forte influência nas características morfofisiológicas das plantas. Em condições de baixa irradiância, observa-se geralmente diminuição na taxa fotossintética líquida $(A)$, decréscimo na razão clorofila $a / b$, diminuição na razão de biomassa entre raiz e parte aérea (R/PA), aumento da área foliar específica (AFE) e da razão de área foliar (RAF), dentre outros, que funcionalmente resultariam em melhor aproveitamento da baixa radiação disponível (BOARDMAN, 1977; FRANCO et al., 2007; GIVNISH, 1988). De modo geral, existem duas estratégias utilizadas pelas plantas para enfrentar as condições de baixa irradiância: (i) alterando o processo de crescimento e desenvolvimento ou (ii) tolerando e mantendo o padrão de crescimento (CARVALHO et al., 2006; SMITH;WHITELAM, 1997).

Atualmente, existem poucos estudos a respeito do comportamento de espécies de Passiflora sob diferentes níveis de sombreamento, relacionando-os a parâmetros fisiológicos importantes ao crescimento, desenvolvimento e à fotossíntese das plantas (SILVA et al., 2006). Além disso, estes estudos tornam-se ainda mais escassos quando se relaciona sombreamento a doses de N. Entretanto, vários trabalhos têm demonstrado que o metabolismo de $\mathrm{N}$ é multirregulado e integrado ao metabolismo geral da planta, uma vez que a absorção de $\mathrm{N}$ requer energia, e essa energia é disponibilizada por carboidratos provindos da fotossíntese (CRUZ et al., 2005; GRECHI et al., 2007).

Respostas fotossintéticas e morfológicas das plantas podem revelar informações a respeito da tolerância de espécies às alterações nas condições de luz, sendo estas informações bastante úteis na ecologia, conservação e, principalmente, no cultivo de espécies tropicais em ambientes naturais e artificiais. O presente trabalho teve como objetivo principal avaliar os efeitos de diferentes níveis de sombreamento e doses de $\mathrm{N}$ nas trocas gasosas foliares, nos teores de pigmentos cloroplastídicos, na anatomia foliar e no crescimento de Passiflora alata.

\section{MATERIAL E MÉTODOS}

\section{Material vegetal e condições de cultivo}

O experimento foi conduzido entre julho de 2008 e fevereiro de 2009 no Câmpus da Universidade Estadual de Santa Cruz - UESC (39 10’W; $14^{\circ}$ 39'S; 78 m), Ilhéus-BA, Brasil. As plantas de $P$. alata foram propagadas assexuadamente por meio de estacas de caule retiradas da parte mediana dos ramos de uma única planta-matriz, preparadas e padronizadas com $20 \mathrm{~cm}$ de comprimento, quatro nós e três folhas reduzidas à metade de sua área original. Depois de secionadas em bisel, suas extremidades basais foram imersas em talco (pó inerte), contendo auxina sintética (ácido indol-3-butírico - AIB) na concentração de $2 \mathrm{~g} \mathrm{~kg}^{-1}$ e estaqueada em leito de areia autoclavada.

Aos 75 dias após o estaqueamento (DAE), as plantas clonais de $P$. alata foram transplantadas 
para vasos plásticos com capacidade para $14 \mathrm{~kg}$ de solo, contendo solo francoarenoso (16,4\% de argila e $79,3 \%$ de areia) como substrato, e submetidas a quatro níveis de sombreamento (0; 25; 50 e 75\%). E dez dias após, aplicaram-se as cinco doses de $\mathrm{N}(0$; 25; 50; 100 e $200 \mathrm{mg} \mathrm{kg}^{-1}$ ) na forma de ureia. Foram consideradas como tratamento-controle as plantas clonais cultivadas sem adição de $\mathrm{N}$ no solo. O substrato utilizado no experimento possuía as seguintes características físico-químicas: $\mathrm{pH}\left(\mathrm{CaCl}_{2}\right)$ 4,7; $\mathrm{Al}^{+++}$ abaixo do limite de detecção; $\mathrm{H}+\mathrm{Al} 2,1 \mathrm{cmol}_{\mathrm{c}} \mathrm{dm}^{3}$; $\mathrm{Ca}^{++} 2,8 \mathrm{cmol}_{\mathrm{c}} \mathrm{dm}^{-3} ; \mathrm{K}^{+} 0,05 \mathrm{cmol}_{\mathrm{c}} \mathrm{dm}^{-3} ; \mathrm{C} 13 \mathrm{~g} \mathrm{dm}^{-3}$; $\mathrm{P}$ (resina) $9 \mathrm{mg} \mathrm{dm}^{-3}$; *V 62,83\%; ${ }^{\mathrm{C} * \mathrm{~T}}$ 5,65 $\mathrm{cmol} \mathrm{dm}^{-3}$ (* saturação por bases; ${ }^{* *}$ CTC a pH 7).

$\mathrm{O}$ solo foi previamente adubado, antes do transplantio, com 6,66 g vaso ${ }^{-1}$ de calcário $\left(\mathrm{CaCO}_{3}\right)$; $19,17 \mathrm{~g}$ vaso ${ }^{-1}$ de superfosfato triplo $\left(\mathrm{P}_{2} \mathrm{O}_{5}\right.$ solúvel em CNA $\left.+\mathrm{H}_{2} \mathrm{O}\right)$; $3,48 \mathrm{~g}$ vaso $^{-1}$ de $\mathrm{KCl}\left(\mathrm{K}_{2} \mathrm{O}\right.$ solúvel em $\mathrm{H}_{2} \mathrm{O}$ ); $0,48 \mathrm{~g} \mathrm{~L}^{-1}$ de $\mathrm{H}_{3} \mathrm{BO}_{3}$; 1 ,29 $\mathrm{g} \mathrm{L}^{-1}$ de $\mathrm{CuSO}_{4}$; e

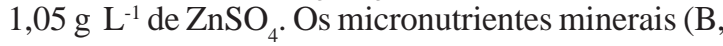
$\mathrm{Zn}$ e $\mathrm{Cu}$ ) foram preparados em uma única solução e aplicados na dosagem de $100 \mathrm{~mL}$ vaso $^{-1}$. Logo após, as plantas clonais de $P$. alata foram transferidas para o telado com os diferentes níveis de sombreamento. Aos 10 dias após o transplantio (DAT), iniciaram-se os tratamentos de $\mathrm{N}$ com aplicação quinzenal de 50 $\mathrm{mL}$ de cada solução (0; 25; 50; 100 e $\left.200 \mathrm{mg} \mathrm{kg}^{-1}\right)$ por vaso.

O sombreamento artificial foi obtido por meio de telas plásticas pretas, com diferentes tipos de malhas, fixadas em armações de madeira com dimensões de 5x5x2 m, em condições de campo. Essas estruturas propiciaram a redução de $25 ; 50$ e $75 \%$ de radiação global total incidente logo abaixo da tela. Armações de arame, com aproximadamente $1 \mathrm{~m}$ de altura, foram fixadas nos vasos, para servirem como suporte na condução das plantas clonais.

O delineamento experimental utilizado foi o inteiramente casualizado, com os tratamentos arranjados no esquema fatorial $4 \times 5$, correspondentes a quatro níveis de sombreamento (0; 25; 50 e 75\%) e cinco doses de $\mathrm{N}$ (0; 25; 50; 100 e $200 \mathrm{mg} \mathrm{kg}^{-1}$ ), com cinco repetições e uma planta clonal por unidade experimental.

\section{Trocas gasosas foliares}

As avaliações de trocas gasosas foliares foram efetuadas aos 175 DAE, entre 8 e 12, em uma folha completamente expandida e madura de cada planta por tratamento. Foram realizadas medições pontuais, utilizando-se de um sistema portátil para medições de fotossíntese LI-6400 (Li-Cor, USA), equipado com uma fonte de luz artificial 6400-02B RedBlue. Durante as medições, a fonte de luz artificial foi ajustada para prover uma densidade de fluxo fotossintético de fótons (DFFF) de $1.000 \mu \mathrm{mol} \mathrm{m}^{-2} \mathrm{~s}^{-1}$, acima da irradiância de saturação e sem provocar fotoinibição; a temperatura e o fluxo de ar foram fixados em $26^{\circ} \mathrm{C}$ e $500 \mu \mathrm{mol} \mathrm{s}^{-1}$, respectivamente. A taxa fotossintética líquida por unidade de área foliar $(A)$, a condutância estomática ao vapor de água ( $g s$ ) e a transpiração foliar $(E)$ foram calculadas usando os valores de $\mathrm{CO}_{2}$, e a variação da umidade do ar no interior da câmara do equipamento, medidos por um analisador de gás infravermelho do sistema portátil de medição de fotossíntese. As outras variáveis calculadas foram a razão da fração molar de $\mathrm{CO}_{2}$ nos espaços aéreos intercelular e atmosférico ( $\mathrm{Ci} / \mathrm{Ca}$ ), e a eficiência instantânea do uso de água $(\mathrm{EUA}=\mathrm{A} / \mathrm{E})$.

\section{Pigmentos cloroplastídicos}

Aos 220 DAE, coletou-se a terceira folha completamente expandida e madura do ramo principal, do ápice para a base, da qual foram retirados seis discos foliares, três dos quais foram, imediatamente após, imersos em 1,0 mL de dimetilsulfóxido (DMSO) em tubos eppendorf envoltos com papel-alumínio e vedados. Em seguida, os tubos foram colocados em banho-maria a $60^{\circ} \mathrm{C}$, por um período de 30 h, para a extração total dos pigmentos cloroplastídicos. Os outros três discos foliares foram colocados em estufa de ventilação forçada de ar, a 75 ${ }^{\circ} \mathrm{C}$, durante $72 \mathrm{~h}$, para a obtenção da biomassa seca. Os teores de clorofila $a, b$ e total foram expressos em $\mathrm{mg} \mathrm{g}^{-1}$ de massa seca (MS) e determinados de acordo com Arnon (1949) e Lichtenthaler (1987), utilizando as seguintes equações: (i) Clorofila $a=$ $\left(12,47 \times \mathrm{A}_{665}\right)-\left(3,62 \times \mathrm{A}_{645}\right)$; (ii) Clorofila $b=(25,06$ $\left.\mathrm{x}_{645}\right)-\left(6,5 \times \mathrm{A}_{665}\right)$; e (iii) Clorofila total $=(20,2 \mathrm{x}$ $\left.\mathrm{A}_{663}-2,69 \times \mathrm{A}_{645} / 1000 \times \mathrm{MS}\right) \mathrm{xV}$; em que $\mathrm{A}_{663}$ e $\mathrm{A}_{645}$ são as absorbâncias em 663 e 645 nm, respectivamente; $\mathrm{V}$ o volume da amostra (mL); e MS a massa seca da amostra (g).

\section{Anatomia foliar}

A anatomia foliar foi observada aos 200 DAE, utilizando-se de amostras do limbo, na região mediana, de três folhas completamente expandidas e maduras por planta. $\mathrm{O}$ material vegetal foi fixado em FAA a $70 \%$, conservado em etanol a $70 \%$, e posteriormente desidratado em uma série etanólica. Em seguida, os cortes transversais à mão livre, obtidos do limbo, foram submetidos à coloração com verde rápido e fucsina básica. Depois, mediu-se a espessura: (i) do parênquima paliçádico (PP) e do lacunoso (PL); (ii) das epidermes abaxiais (EPAB) e e adaxiais (EPAD); e (iii) do mesofilo foliar, utilizando um microscópio óptico Laica modelo DMI-3000 
B, contendo o software Laica application suite V3. Durante as medições, utilizaram-se dez campos distintos em três repetições de cada tratamento.

\section{Parâmetros de crescimento}

No final do período experimental, aos 220 DAE, coletaram-se as plantas clonais dos diversos tratamentos. Imediatamente após, fez-se a separação das plantas em raiz, caule e folhas, e mediu-se a área foliar, utilizando um medidor automático modelo Li-3100 (Li-Cor, Nebraska, USA). Logo após, os diferentes órgãos foram armazenados separadamente, em sacos de papel, e colocados em estufa de ventilação forçada de ar, a $75^{\circ} \mathrm{C}$, para secagem, até massa constante. A partir da biomassa seca dos diferentes órgãos, foi determinada a razão raiz/parte aérea (R/PA), obtida pela razão entre a biomassa seca de raiz e a biomassa seca do caule e das folhas.

\section{Análise estatística}

Os resultados referentes às trocas gasosas foliares e aos parâmetros de crescimento foram submetidos à análise de variância (ANOVA) e de superfície de resposta. Testou-se a significância dos coeficientes dos modelos matemáticos $(\mathrm{p}<0,05)$. Os dados de pigmentos cloroplastídicos e a anatomia foliar foram submetidos à análise de variância (ANOVA) e comparados pelo teste de Tukey $(p<0,05)$.

\section{RESULTADOS E DISCUSSÃO}

\section{Trocas gasosas foliares}

Ocorreu interação significativa $(\mathrm{p}<0,05)$ entre níveis de sombreamento (NS) e doses de nitrogênio $(\mathrm{N})$ para todas as variáveis de trocas gasosas foliares avaliadas. A taxa fotossintética líquida (A) aumentou com o incremento do sombreamento e as doses de N, observando-se um efeito quadrático tanto para sombreamento quanto para $\mathrm{N}$ (Figura 1). O valor máximo de $A$ foi obtido na dose correspondente a $146 \mathrm{mg} \mathrm{N} \mathrm{kg}^{-1}$ de solo a $75 \%$ de sombreamento. Por outro lado, os valores máximos para condutância estomática ao vapor de água ( $g s)$ e à transpiração foliar $(E)$ foram encontrados em 33 e $50 \%$ de sombreamento, respectivamente, na dose de $137 \mathrm{mg} \mathrm{N} \mathrm{kg}^{-1}$ (Figuras 2 e 3).

O acréscimo nos valores de $A$, com o incremento do sombreamento e o aumento do suprimento de $\mathrm{N}$ até $146 \mathrm{mg} \mathrm{N} \mathrm{kg}^{-1}$, e o decréscimo nas doses subsequentes podem estar relacionados ao conteúdo de $\mathrm{N}$ no solo e nas plantas clonais. Pois, baixa disponibilidade desse nutriente para as plantas pode ocasionar diminuição do número e do tamanho dos componentes fotossintéticos, ao passo que um suprimento maior de $\mathrm{N}$ pode promover uma redução na abertura dos estômatos, devido ao efeito negativo de doses elevadas de $\mathrm{N}$ sobre a condutância do mesofilo (CRUZ et al., 2005). O mesmo fato foi observado também em plantas jovens de Theobroma cacao, onde os efeitos de diferentes níveis de sombreamento e doses de $\mathrm{N}$ proporcionaram acréscimo de $A$ até uma determinada dose de $\mathrm{N}$, e decréscimo em doses de $\mathrm{N}$ mais elevadas (COSTA et al., 2001).

Resultados positivos de $A$, com o incremento nas doses de $\mathrm{N}$, devem-se à maior biossíntese de componentes fotossintéticos, dos quais o $\mathrm{N}$ é constituinte, tais como a enzima Rubisco e a molécula de clorofila (CABREBA-BOSQUET et al., 2009; POMPEU et al., 2010). Além disso, os dados obtidos mostraram similaridade no comportamento de $g$ s e $A$, sugerindo controle das trocas gasosas por fatores estomáticos (OLIVEIRA et al., 2006), uma vez que há relação direta entre $g$ s e $A$, de modo que o aumento de $g s$ promove incremento em $A$ (LIMA JÚNIOR et al., 2006).

Plantas clonais de $P$. alata cultivadas sem a adição de $\mathrm{N}$ no solo apresentaram maiores valores de $A$, em $75 \%$ de sombreamento, em relação às cultivadas a pleno sol (Figura 1). O decréscimo de $A$ em folhas maduras, totalmente expostas à luz, particularmente no tratamento sem adição de N, pode estar relacionado ao acúmulo de carboidratos solúveis em nível foliar, resultante de uma produção excedente de fotoassimilados (MOHOTTI; LAWLOR, 2002). Este acúmulo reduz a demanda dos drenos metabólicos por fotoassimilados, induzindo uma redução de A. Além disso, temperaturas elevadas, o que provavelmente ocorreu no tratamento a pleno sol, promovem decréscimo em A (FREITAS et al., 2003). O acréscimo de gs e $E$, com a adição de $\mathrm{N}$ até a dose de $137 \mathrm{mg} \mathrm{N} \mathrm{kg}^{-1}$, se deve- se a maior produção de biomassa seca foliar, promovida pelo incremento na adubação nitrogenada, tendo como consequência aumento de $A$ e na demanda hídrica da planta, ocorrendo maior absorção de água pelo sistema radicular (POMPEU et al., 2010).

\section{Pigmentos cloroplastídicos}

No tratamento-controle para todos os pigmentos cloroplastídicos avaliados, não houve diferença significativa $(\mathrm{p}<0,05)$ entre os níveis de sombreamento. Entretanto, essa diferença foi observada para os demais tratamentos com $\mathrm{N}$. Os teores de clorofila $a, b$ e total $(a+b)$ apresentaram respostas lineares e aumentaram com a elevação dos níveis de sombreamento, cujos maiores teores foram obtidos em $75 \%$ de sombreamento. Em contrapartida, houve redução na razão clorofila $a / b$ com o incremento dos níveis de sombreamento apenas na dose de $25 \mathrm{mg} \mathrm{N} \mathrm{kg}^{-1}$, 
não sendo significativa $(\mathrm{p}<0,05)$ nos demais tratamentos com N (Tabela 1). No tratamento com $50 \%$ de NS, observou-se aumento significativo nos teores de clorofila $a$, $b$ e total entre o tratamento-controle e a menor dose de N. Os maiores teores de clorofila $b$ foram encontrados em $75 \%$ de sombreamento na dose correspondente a $200 \mathrm{mg} \mathrm{N} \mathrm{kg}^{-1}$ de solo. Resultados similares foram obtidos para plantas jovens de $T$. cacao, onde também se observou que os teores de clorofila foram maiores nas plantas mais sombreadas e especialmente nas doses mais elevadas de $\mathrm{N}$ (COSTA et al., 1998). Geralmente, isto se deve à alta correlação existente entre o teor de $\mathrm{N}$ e de clorofila nas folhas, visto que este nutriente mineral é constituinte da molécula de clorofila.

As respostas dos teores de pigmentos fotossintéticos, em função dos níveis de sombreamento, corroboram os resultados encontrados em $P$. edulis (ZANELLA et al., 2006) e $P$. morifolia, $P$. suberosa e P. palmeri (PIRES et al., 2011). Por outro lado, as respostas em função das doses de $\mathrm{N}$ foram similares às encontradas em $P$. edulis por Silva et al. (2006). Isto, por sua vez, deve- se ao fato de que a maior parte de $\mathrm{N}$ foliar está associada às proteínas cloroplastídicas e ao teor de clorofilas. Logo, aumento no suprimento de $\mathrm{N}$ promove elevação do teor de clorofila e,consequentemente, da capacidade fotossintética das plantas (HIROSE; BAZZAZ, 1998; MOHOTTI; LAWLOR, 2002). A diminuição da razão clorofila $a / b$, com o aumento do sombreamento, deve- se ao aumento na concentração de clorofila $b$ em ambientes mais sombreados (BOARDMAN, 1977). Entretanto, em $P$. alata, esta diminuição foi pouco significativa $(\mathrm{p}<0,05)$, e os teores de clorofila $a$ foram superiores aos de clorofila $b$ em todos os tratamentos, corroborando os resultados encontrados para $P$. morifolia, $P$. suberosa e P. palmeri (PIRES et al., 2011).

\section{Anatomia foliar}

Os maiores valores médios de espessura encontrados para parênquima paliçádico (PP); parênquima lacunoso (PL); epiderme abaxial (EPAB); epiderme adaxial (EPAD) e mesofilo foram de 72,3; 164,4 ; 18,9; 39,7 e 297,0 $\mu \mathrm{m}$, respectivamente, obtidos a pleno sol, no tratamento-controle, ao passo que os menores valores foram de 14,1; 30,5; 6,2; 9,9 e $60,5 \mu \mathrm{m}$, respectivamente, encontrados a $75 \%$ de sombreamento e na dose correspondente a $50 \mathrm{mg} \mathrm{N}$ $\mathrm{kg}^{-1}$ de solo. Observou-se redução da espessura do mesofilo foliar com a elevação dos níveis de sombreamento (Tabela 2). O mesmo fato foi verificado para T. cacao (COSTA et al., 1998), P. edulis (SILVA et al., 2006), P. morifolia, P. suberosa e P. palmeri (PIRES et al., 2011).
O aumento da espessura do mesofilo foliar e das epidermes adaxial e abaxial com a diminuição do sombreamento, provavelmente, é uma estratégia de aclimatação das plantas clonais de $P$. alata a ambiente com estresse por alta irradiância. Já a diminuição de PP com o incremento do sombreamento deve-se à redução do comprimento e da largura das células que compõem esse tecido (GONDIM et al., 2008), e ao maior investimento na expansão foliar. A plasticidade fenotípica foliar, em relação às variações da irradiância, está diretamente associada com as trocas gasosas; desta forma, alterações nestas características favorecem um melhor desenvolvimento de plantas sob diferentes condições ambientais (LIMA JÚNIOR et al., 2006; BOEGER; POULSON, 2006). As propriedades do mesofilo, principalmente as do parênquima paliçádico, garantem a absorção uniforme da luz através da folha, sendo a anatomia foliar especializada para a captação de luz (NASCIMENTO et al., 2006).

Em mudas clonais de $P$. alata cultivadas a pleno sol, ocorreu redução significativa $(\mathrm{p}<0,05)$ na espessura do parênquima paliçádico (PP), parênquima lacunoso (PL), epiderme abaxial (EPAB), epiderme adaxial (EPAD) e mesofilo foliar, com a adição de doses de $\mathrm{N}$.

\section{Parâmetros de crescimento}

Não houve interação NS x N para área foliar (AF); entretanto, esta variável de crescimento apresentou diferenças significativas $(\mathrm{p}<0,05)$ para NS e doses de $\mathrm{N}$, isoladamente. Os maiores valores de AF foram obtidos entre 25 e $50 \%$ de sombreamento, alcançando o valor máximo em $45 \%$ de sombreamento. Também foi observado incremento de AF com o fornecimento de $\mathrm{N}$ até a dose correspondente a $122 \mathrm{mg} \mathrm{N} \mathrm{kg}^{-1}$ de solo, reduzindo-se nas doses subsequentes (Figura 4).

$\mathrm{O}$ aumento de AF, em plantas submetidas a ambientes sombreados, deve-se ao incremento da expansão foliar para captar maior quantidade de energia solar disponível, garantindo, assim, seu processo fotossintético (ALMEIDA et al., 2005; SABBI et al., 2010; COELHO et al., 2010). Além disso, o aumento da superfície fotossintetizante é uma forma de as plantas assegurarem um aproveitamento maior das baixas intensidades de radiação luminosa (AGUILERA et al., 2004).

Geralmente, o incremento da adubação nitrogenada promove maior crescimento vegetativo da planta, incluindo maior incremento em biomassa foliar, expansão da área foliar e, consequentemente, aumento na taxa fotossintética das plantas, ao passo que a deficiência de $\mathrm{N}$ promove redução de $\mathrm{AF}$. Em 
mudas de $P$. edulis, também foi observado aumento de AF com o incremento de $\mathrm{N}$ até uma dose considerada ótima para esta espécie (ALMEIDA et al., 2006).

Os maiores valores para biomassa seca de raiz (BSR), caule (BSC), folha (BSF) e total (BST) foram encontrados entre 25 e $69 \%$ de sombreamento, reduzindo-se nos níveis mais elevados de sombreamento. Houve incremento das variáveis BSC, BSF e BST com a adição de N, obtendo-se os valores máximos nas doses correspondentes a 122; 200 e $113 \mathrm{mg}$ $\mathrm{N} \mathrm{kg}^{-1}$ de solo, respectivamente (Figura 5). Ocorreu incremento de $18,48 \%$ na BST entre o tratamento-controle e a menor dose de $\mathrm{N}$ adicionada (25 mg N $\mathrm{kg}^{-1}$ ). O acréscimo em biomassa seca com a elevação das doses de $\mathrm{N}$ até uma dose máxima, seguido de decréscimo nas doses subsequentes, também foi verificado em P. edulis (AIYELAAGBE et al., 2005; NATALE et al., 2006; SILVA et al., 2006; ALMEIDA et al., 2006) e $P$. alata (SOUZA et al., 2007).

O acréscimo de BSR, BSC, BSF e BST com a elevação das doses de $\mathrm{N}$ até uma dose máxima, seguido de decréscimo nas doses subsequentes, provavelmente, está relacionado com a elevação da fotossíntese líquida. Entretanto, a redução dessa biomassa, a partir das doses mais elevadas de $\mathrm{N}$, relaciona-se com a diminuição de $g s$ e, consequentemente, com a redução de $A$. Este fato se deve ao desequilíbrio entre a fotossíntese e a respiração, ocasionado por pesadas adubações nitrogenadas. Quando o suprimento de $\mathrm{N}$ e os níveis de luz se encontram dentro de uma faixa de "combinação harmoniosa", a eficiência da fotossíntese, o crescimento e a produção de biomassa seca são máximos (COSTA et al., 1998).

Não houve influência dos níveis de sombreamento para a razão raiz/parte aérea (R/PA), porém esta razão diminuiu com o incremento de $\mathrm{N}$ até a dose correspondente a $100 \mathrm{mg} \mathrm{N} \mathrm{kg}^{-1}$, ocorrendo efeito quadrático em função das doses de $\mathrm{N}$, e linear em função do sombreamento (Figura 6). Provavelmente, em $P$. alata, a deficiência de $\mathrm{N}$ promoveu maior crescimento de raiz, enquanto o suprimento adequado de $\mathrm{N}$ favoreceu o desenvolvimento da parte aérea. Desta forma, o decréscimo da razão R/ PA, com a elevação das doses de N, deveu- se ao direcionamento de maior proporção de partição de fotoassimilados para as folhas.

Diferença na razão R/PA entre os tratamentos de sombreamento também foi verificada em Cryptocaria aschersoniana (ALMEIDA et al., 2004). Entretanto, esses resultados observados no presente trabalho, em função dos níveis de sombreamento, contrastam com aqueles encontrados para outras espécies perenes, como $P$. edulis (SILVA et al., 2006); Bombacopsis glabra (SCALON et al., 2003); Cecropia glazioui, Cedrela fissillis, Bathysa australis (DUZ et al., 2004). A redução de R/PA, com a elevação das doses de $\mathrm{N}$, também foi verificada para Vitis vinifera, onde não houve efeito de N na BST, porém o $\mathrm{N}$ modificou significativamente o padrão de partição de biomassa seca entre raiz e parte aérea (GRECHI et al., 2007).

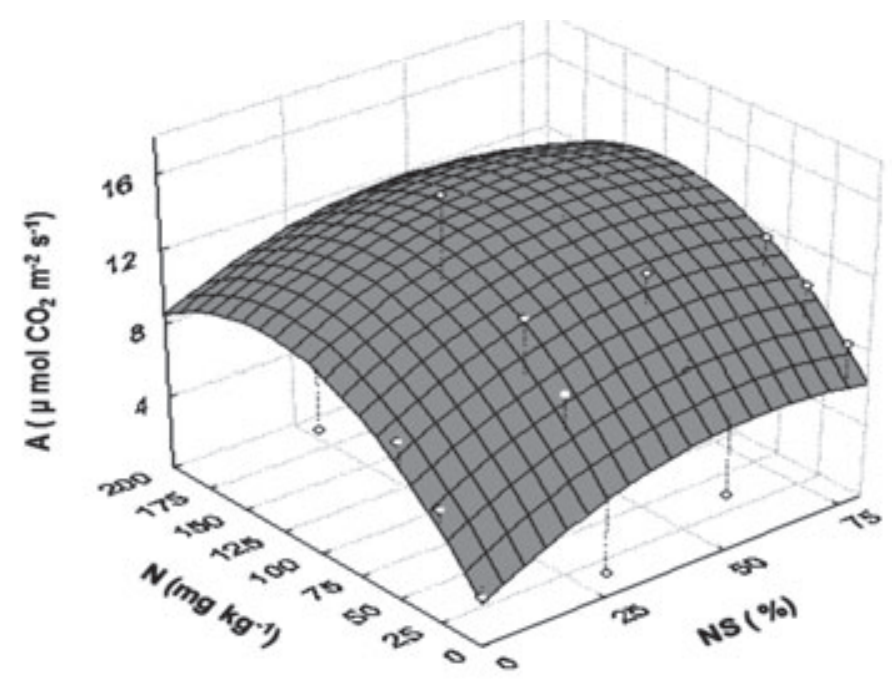

FIGURA 1 - Taxa de fotossíntese líquida (A) em folhas de plantas clonais de Passiflora alata submetidas a doses de $\mathrm{N}$ e níveis de sombreamento (NS). $\hat{\mathrm{Y}}=2,66+0,15^{* * *} \mathrm{NS}+0,117 * * * \mathrm{~N}-0$, $001 * * * \mathrm{NS}^{2}-0,0004 * * * \mathrm{~N}^{2}\left(\mathrm{R}^{2}=0,60\right)$. 


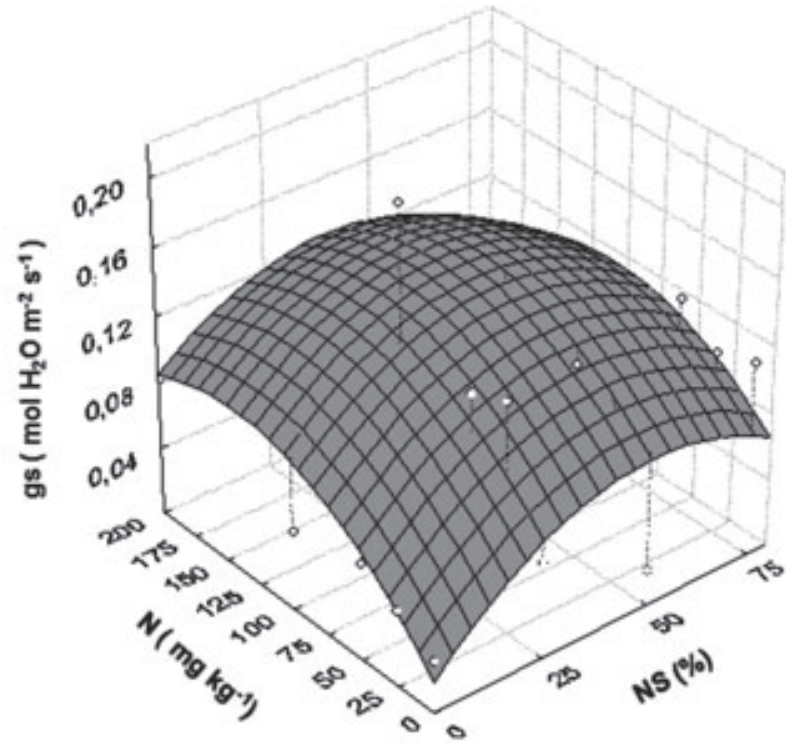

FIGURA 2 - Condutância estomática ao vapor de água (gs) em folhas de plantas clonais de Passiflora alata submetidas a doses de $\mathrm{N}$ e níveis de sombreamento (NS). $\hat{\mathrm{Y}}=0,027+$ $0,002 * * * N S+0,0009 * * * N+0,00003 * * * \mathrm{NS}^{2}+0,000 * * * \mathrm{~N}^{2}\left(\mathrm{R}^{2}=0,40\right)$.

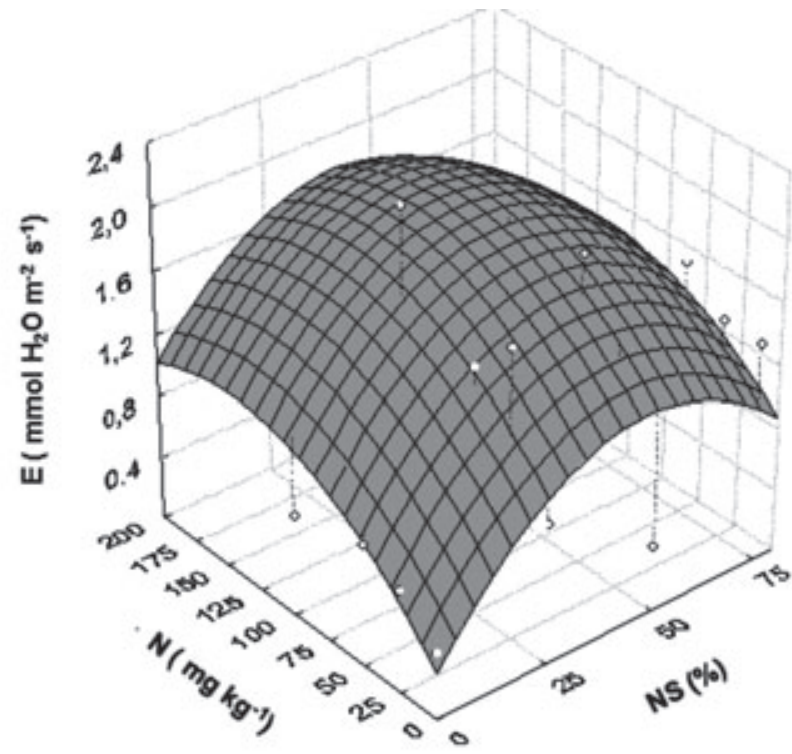

FIGURA 3 - Taxa de transpiração (E) em folhas de plantas clonais de Passiflora alata submetidas a doses de $\mathrm{N}$ e níveis de sombreamento (NS). $\hat{\mathrm{Y}}=0,37+0,04^{* * *} \mathrm{NS}+0.011^{* * *} \mathrm{~N}-0,0004 * * *$ $\mathrm{NS}^{2}-0,00004^{* * *} \mathrm{~N}^{2}\left(\mathrm{R}^{2}=0,55\right)$. 


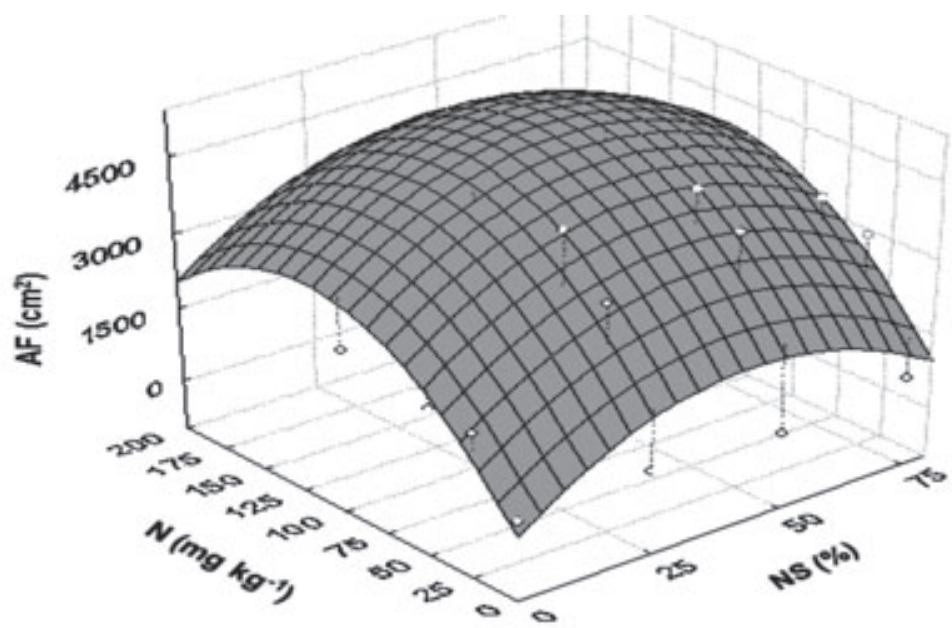

FIGURA 4 - Área foliar total por planta (AF) em plantas clonais de Passiflora alata submetidas a doses de $\mathrm{N}$ e níveis de sombreamento (NS). $\hat{\mathrm{Y}}=277,28+80,30 * * * \mathrm{NS}+48,65^{* * *} \mathrm{~N}-0,89 * * *$ $\mathrm{NS}^{2}-0,199 * * * \mathrm{~N}^{2}\left(\mathrm{R}^{2}=0,75\right)$.

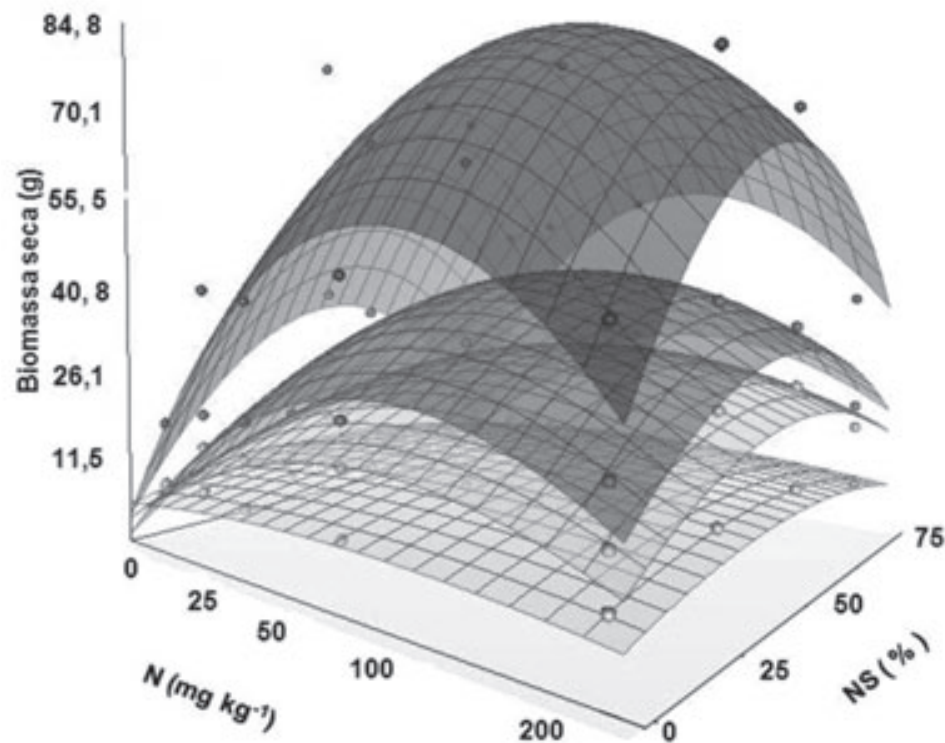

FIGURA 5 - Biomassa seca total (azul); biomassa seca foliar (vermelho); biomassa seca de caule (verde) e biomassa seca de raiz (cinza) em plantas clonais de Passiflora alata submetidas a doses de $\mathrm{N}$ e níveis de sombreamento (NS). BST $\hat{\mathrm{Y}}=0,038+1,70 * * \mathrm{NS}+1,48 * * \mathrm{~N}-0,78^{* *} \mathrm{NS}^{2}$ $0,87 * * \mathrm{~N}^{2}\left(\mathrm{R}^{2}=0,65\right)$; BSF $\hat{\mathrm{Y}}=-0,022+0,98 * * * \mathrm{NS}+0,73 * * \mathrm{~N}-0,44 * * \mathrm{NS}^{2}-0,44 * * \mathrm{~N}^{2}$ $\left(\mathrm{R}^{2}=0,70\right) ; \mathrm{BSC} \hat{\mathrm{Y}}=0,027+0,59 * * \mathrm{NS}+0,53 * * \mathrm{~N}-0,27 * * \mathrm{NS} 2-0,29 * * \mathrm{~N}^{2}\left(\mathrm{R}^{2}=0,67\right)$; BSR $\hat{Y}=5,40+0,20 * * N S-0,002 * * \mathrm{NS}^{2}\left(\mathrm{R}^{2}=0,30\right)$. 


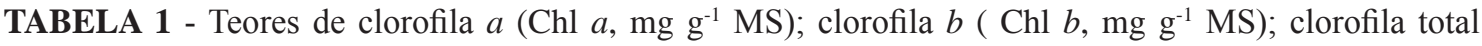
(Chl t, mg g $\left.{ }^{-1} \mathrm{MS}\right)$; razão clorofila $a / b\left(\mathrm{Chl} a / b\right.$, $\mathrm{mg} \mathrm{g}^{-1} \mathrm{MS}$ ) em folhas de plantas clonais de Passiflora alata submetidas a diferentes níveis de sombreamento e doses de $\mathrm{N}$, aos 110 dias após o transplantio.

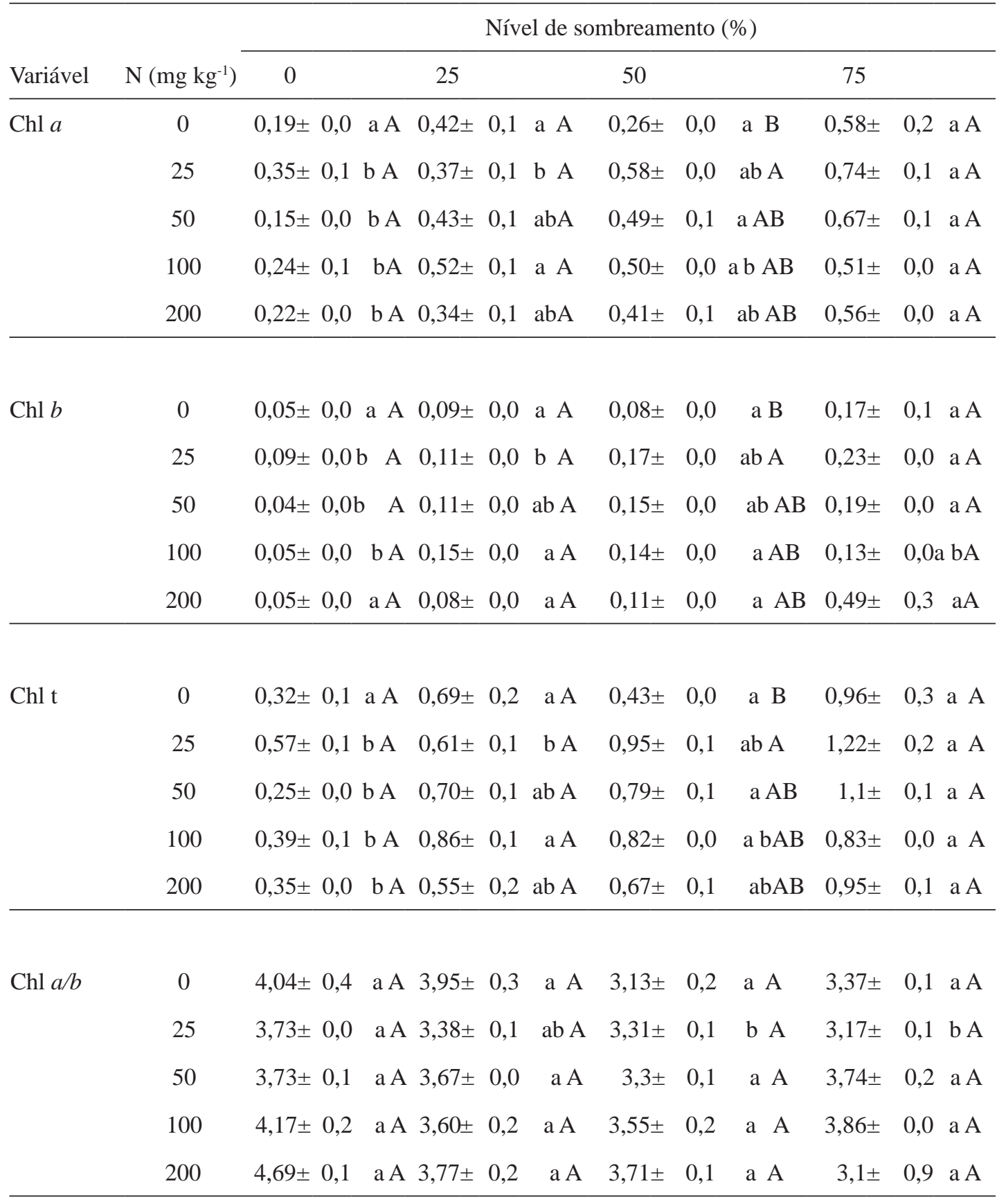

Letras minúsculas indicam comparação entre tratamento de sombreamento, e as maiúsculas entre doses de $\mathrm{N}$ pelo teste de Tukey (p<0,05). 
TABELA 2- Espessuras de parênquima paliçádico (PP, $\mu \mathrm{m})$; parênquima lacunoso (PL, $\mu$ m); epiderme abaxial (EPAB, $\mu \mathrm{m})$; epiderme adaxial (EPAD, $\mu \mathrm{m})$, e mesofilo $(\mu \mathrm{m})$, em folhas de plantas clonais de Passiflora alata, submetidas a diferentes níveis de sombreamento e doses de N. Valores médios de 5 repetições ( \pm EP).

\begin{tabular}{|c|c|c|c|c|c|c|c|c|c|c|}
\hline \multirow[b]{2}{*}{ Variável } & \multirow[b]{2}{*}{$\mathrm{N}\left(\mathrm{mg} \mathrm{kg}^{-1}\right)$} & \multicolumn{9}{|c|}{ Nível de sombreamento (\%) } \\
\hline & & 0 & 25 & & & 50 & & & 75 & \\
\hline \multirow[t]{5}{*}{$\mathrm{PP}$} & 0 & $72,3 \pm 2,9$ a A & $47,3 \pm$ & 3,2 & b A & 51,5 & $\pm 1,1$ & b A & $28,8 \pm 1,8$ & $\mathrm{CAB}$ \\
\hline & 25 & $49,9 \pm 1,2$ a B & $48,8 \pm$ & 1,5 & a A & 39,7 & $\pm 2,1$ & b B & $29,7 \pm 1,0$ & c A \\
\hline & 50 & $52,9 \pm 1,5$ a B & $48,4 \pm$ & 1,7 & a A & 41,6 & $\pm 1,8$ & b B & $14,1 \pm 1,2$ & с C \\
\hline & 100 & $51,3 \pm 1,0$ a B & $44,7 \pm$ & 1,6 & b A & 44,5 & $\pm 2,0$ & b B & $22,4 \pm 1,8$ & c B \\
\hline & 200 & $52,8 \pm 1,8$ a B & $47,7 \pm$ & 0,9 & a A & 47,1 & $\pm 1,0$ & a $\mathrm{AB}$ & $29,2 \pm 2,8$ & $\mathrm{~b} A B$ \\
\hline \multirow[t]{5}{*}{$\mathrm{PL}$} & 0 & $164,4 \pm 3,6$ a $A$ & $96,2 \pm$ & 6,3 & c C & 119,1 & $\pm 2,7$ & b A & $61,2 \pm 5,8$ & $\mathrm{~d} A B$ \\
\hline & 25 & $131,9 \pm 1,1$ a C & $120,9 \pm$ & 3,7 & a B & 100,8 & $\pm 5,0$ & b A & $75,1 \pm 1,3$ & c A \\
\hline & 50 & $129,5 \pm 2,2$ a C & $125,8 \pm$ & 3,4 & a $\mathrm{AB}$ & 115,7 & $\pm 7,0$ & a A & $30,5 \pm 2,3$ & b C \\
\hline & 100 & $145,5 \pm 2,1$ a B & $139,8 \pm$ & 3,4 & a A & 117,2 & $\pm 6,0$ & b A & $51,4 \pm 3,7$ & $\mathrm{c} B$ \\
\hline & 200 & $135 \pm 3,3$ а C & $117,4 \pm$ & 2,6 & b B & 115,1 & $\pm 2,3$ & b A & $52,7 \pm 4,3$ & c B \\
\hline \multirow[t]{5}{*}{ ЕРAB } & 0 & $18,9 \pm 0,8$ a $A$ & $13,4 \pm$ & 0,9 & $\mathrm{bA}$ & 17,9 & $\pm 0,6$ & $\mathrm{aA}$ & $8,9 \pm 0,9$ & c A \\
\hline & 25 & $15,3 \pm 0,4$ a B & $15,8 \pm$ & 0,5 & a $\mathrm{AB}$ & 14,5 & $\pm 0,7$ & $\mathrm{aB}$ & $10,4 \pm 0,3$ & b A \\
\hline & 50 & $13,8 \pm 0,4 \quad b B$ & $17,3 \pm$ & 0,6 & a A & 15,2 & $\pm 1,0$ & abAB & $6,2 \pm 0,5$ & c B \\
\hline & 100 & $14,5 \pm 0,4$ a B & $16,2 \pm$ & 0,4 & a A & 15,3 & $\pm 0,7$ & $\mathrm{aAB}$ & $8,0 \pm 0,7$ & b AB \\
\hline & 200 & $14,9 \pm 0,4$ a B & $15,0 \pm$ & 0,5 & a $\mathrm{AB}$ & 16,5 & $\pm 0,4$ & $\mathrm{aAB}$ & $9,5 \pm 0,9$ & b A \\
\hline \multirow[t]{5}{*}{ EPAD } & 0 & $39,7 \pm 1,2$ a $A$ & $26,3 \pm$ & 1,7 & b A & 28,8 & $\pm 0,5$ & b A & $17,5 \pm 1,6$ & c A \\
\hline & 25 & $28,7 \pm 0,3$ а $\mathrm{B}$ & $30,5 \pm$ & 0,5 & a $A B$ & 24,4 & $\pm 1,2$ & b B & $17,6 \pm 0,4$ & c A \\
\hline & 50 & $30,2 \pm 0,6$ b $\mathrm{B}$ & $34,0 \pm$ & 0,8 & a A & 24,9 & $\pm 0,8$ & c B & $9,9 \pm 0,9$ & $\mathrm{~d} B$ \\
\hline & 100 & $29,3 \pm 0,5 \mathrm{abB}$ & $32,2 \pm$ & 1,3 & a $\mathrm{AB}$ & 27,1 & $\pm 1,1$ & $\mathrm{~b} A B$ & $15,6 \pm 1,1$ & c A \\
\hline & 200 & $31,2 \pm 0,7$ a $\mathrm{B}$ & $28,5 \pm$ & 0,6 & a B & 30,2 & $\pm 0,4$ & a $\mathrm{A}$ & $16,4 \pm 1,4$ & b A \\
\hline
\end{tabular}

\begin{tabular}{lcccccccc}
\hline Mesofilo & 0 & $297,0 \pm 2,3$ & a A $186,2 \pm 11,5$ & c B & $219,1 \pm 2,7$ & b A & $116,0 \pm 9,8$ & d AB \\
& 25 & $225,6 \pm 1,5$ & a C $216,1 \pm 4,7$ & a A & $176,9 \pm 8,3$ & b B & $130,4 \pm 1,0$ & c A \\
& 50 & $226,3 \pm 2,6$ & a C $226,0 \pm 5,3$ & a A & $196,6 \pm 9,8$ & b AB $60,5 \pm 4,8$ & c C \\
& 100 & $239,0 \pm 2,7$ & a B $218,6 \pm 6,5$ & ab A & $202,4 \pm 9,0$ & b AB $96,0 \pm 6,9$ & c B \\
& 200 & $235,4 \pm 4,3$ a BC $207,8 \pm 3,5$ & bAB $208,2 \pm 2,9$ & b A $106,1 \pm 8,9$ & c AB \\
\hline
\end{tabular}

Letras minúsculas indicam comparação entre tratamentos com sombreamento, e letras maiúsculas entre doses de $\mathrm{N}$, pelo teste de Tukey $(\mathrm{p}<0,05)$. 


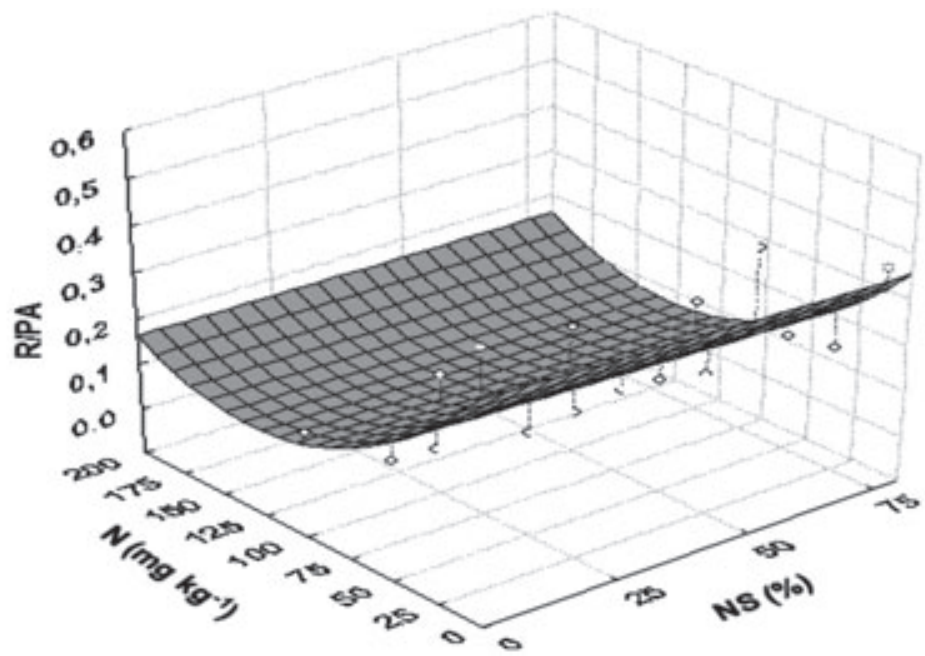

FIGURA 6 - Razão raiz/parte aérea (R/PA) em plantas clonaisde $P$. alata submetidas a doses de $\mathrm{N}$ e níveis de sombreamento (NS). $\hat{Y}=0,37-0,004 * * * N+0,00002 * * * N^{2}\left(R^{2}=0,70\right)$.

\section{CONCLUSÕES}

1-O sombreamento moderado (25 e $50 \%$ ), associado a um suprimento adequado de $\mathrm{N}$ (sem deficiência ou excesso), promove maior eficiência fotossintética e, consequentemente, maior partição de biomassa seca para a parte aérea, em relação às plantas cultivadas em baixa e em alta irradiância. Por outro lado, em condições de baixa irradiância, as plantas de $P$. alata demonstraram grande plasticidade morfofisiológica, principalmente a foliar.

2-O excesso de adubação nitrogenada, em condições de alta (pleno sol) ou de baixa irradiância (75\% de sombreamento), comprometeo crescimento e o desenvolvimento das plantas de Passiflora alata.

3-Os resultados obtidos no presente trabalho possibilitam inferir que o cultivo de Passiflora alata deve ser realizado em condições de $25 \%$ de sombreamento, com uma adubação inicial de crescimento em torno de 100 a 120 mg de $\mathrm{N} \mathrm{kg}^{-1}$.

\section{AGRADECIMENTOS}

Ao Programa de Pós-Graduação em Produção Vegetal da UESC e à equipe do Centro de Microscopia da UESC; ao CNPq, pela concessão da bolsa de Mestrado; e ao pós- graduando Emerson Santos.

\section{REFERÊNCIAS}

AGUILERA, D. B.; FERREIRA, F. A.; CECON, P. R. Crescimento de Siegesbeckia orientalis sob diferentes condições de luminosidade. Planta Daninha, Viçosa,MG, v. 22, n. 1, p. 43-51, 2004.

AIYELAAGBE, I. O. O.; FAGBAYIDE, J.A.; MAKINDE, A. I. Effects of $\mathrm{N}$ fertilization on the vegetative growth of passion fruit (Passiflora edulis f. flavicarpa) seedlings. Journal of Food, Agriculture \& Environment, Ibadan, v. 3, p. 62-64, 2005.

ALMEIDA, L. P.; ALVARENGA, A. A.; CASTRO, E. M.; ZANELA, S. M.; VIEIRA, C. V.; Crescimento inicial de plantas de Cryptocaria aschersoniana Mez. submetidas a níveis de radiação solar. Ciência Rural, Santa Maria, v.34, n.1, p.83-88, 2004.

ALMEIDA, E. V.; NATALE, W.; PRADO, R. M.; BARBOSA, J. C. Adubação nitrogenada e potássica no desenvolvimento de mudas de maracujazeiro. Ciência Rural, Santa Maria, v.36, n.4, jul.-ago. 2006.

ALMEIDA, S. M. Z.; SOARES, A. M.; CASTRO, E. M.; VIEIRA, C. V.; GAJEGO, E. B. Alterações morfológicas e alocação de biomassa em plantas jovens de espécies florestais sob diferentes condições de sombreamento. Ciência Rural, Santa Maria, v.35, n.1, p.62-68, 2005. 
ARNON, D. I. Copper enzymes in isolated chloroplast: polyphenoloxidase in Beta vulgaris. Plant Physiology, Rockville, v. 24, n. 1, p. 1-15, 1949.

BOARDMAN, N. K. Comparative photosynthesis of sun and shad plants. Annual Review of Plant Physiology, Palo Alto, v.28, p.355-377, 1977.

BOEGER, M.R.T.; POULSON, M. E. Efeitos da radiação utravioleta-B sobre a morfologia foliar de Arabidopsis thaliana (L.) Heynh. (Brassicaceae). Acta Botanica Brasilica, Porto Alegre, v.20, n. 2, p.329-338, 2006.

CABRERA-BOSQUET, L.; ALBRIZIO, R.; ARAUS, J.L.; NOGUÉS, S. Photosynthetic capacity of field-grown durum wheat under different $\mathrm{N}$ availabilities: A comparative study from leaf to canopy. Environmental and Experimental Botany, Elmsford, v.6, n.1, p.145- 152, 2009.

CARVALHO, L.M.; CASALI, V.W.D.; LISBOA, S.P.; BARBOSA, L.C.A.; CECON, P.R. Crescimento e metabolismo em artemísia em função do nível de irradiância. Horticultura Brasileira, Brasília, v. 24, n.3, p.289-294, 2006.

COELHO, R.A.; MATSUMOTO, S.N.; LEMOS, C.L.; SOUZA, F.A. Nível de sombreamento, umidade do solo e morfologia do cafeeiro em sistemas agroflorestais. Revista Ceres, Viçosa, MG, v.57, n.1, p.95-102, 2010.

COSTA, L. C. B.; ALMEIDA, A. F.; VALLE, R. R. Crescimento, teor de clorofila e estrutura anatômica em plântulas de Theobroma cacao submetidas a diferentes irradiância e doses de nitrogênio. Agrotrópica, Itabuna, v. 10, n. 1, p. 21-30, 1998.

COSTA, L. C. B.; ALMEIDA, A. A. F.; VALLE, R. R. Gas exchange, nitrate assimilation and drymatter accumulation of Theobroma cacao seedlings submitted to different irradiances and nitrogen levels. Journal of Horticultural Science \& Biotechnology, Ashford, , v.76, n.2, p.224-230, 2001.

CRUZ, J.L.; CARVALHO, J.E.B.; COELHO, E.F.; FILHO, L.F.S.S.; QUEIROZ, D.C. Efeito da deficiência de nitrogênio sobre a assimilação de carbono do mamoeiro ‘golden'. In: SIMPOSIO DO PAPAYA BRASIL, 2., 2005, Vitória. Anais... Vitória: Incaper, 2005. p.347-350, 2005.
DUZ, R.S.; SIMINSKI, A.; SANTOS, S.; PAULILO, M.T.S. Crescimento inicial de três espécies arbóreas da floresta atlântica em resposta à variação na quantidade de luz. Revista Brasileira Botânica, São Paulo, v.27, n.3, p.587-596, 2004.

FRANCO, A.M.S.; DILLENBURG, L.R. Ajustes morfológicos e fisiológicos em plantas jovens de Araucaria angustifolia (Bertol.) Kuntze em resposta ao sombreamento. Hoehnea, São Paulo, v.34, n.2, p.135-144, 2007.

FREITAS, M.S.M. Flavonoides e nutrientes minerais em folhas de maracujazeiro- amarelo e deficiência de macronutrientes e boro em maracujazeiro-doce. 2006. 106 f. Tese (Doutorado em produção vegetal) - Universidade Estadual do Norte Fluminense Darcy Ribeiro, Centro de Ciências e Tecnologias Agropecuárias, Campos dos Goytacazes, 2006.

FREITAS, R.B.; OLIVEIRA, L.E.M.; FILHO, N.D.; SOARES, A.M. Influência de diferentes níveis de sombreamento no comportamento fisiológico de cultivares de café (Coffea arabica L.). Ciência e Agrotecnologia, Lavras, v.27, n.4, p.804-810, 2003.

GIVNISH, T.J. Adaptation to sun and shade: A whole - plant perspective. Australian Journal of Plant Physiology, Melbourne, n.15, p.63-92, 1988.

GONÇALVES, C.G. Cultivo em campo de Coffea arabica L. cv . Obatã a pleno sol x sombreamento parcial: avaliações bioquímicas, fisiológicas e nutricionais. 2007. 117f Tese (Doutorado) - Escola Superior de Agricultura “Luiz de Queiroz”, Universidade de São Paulo, Piracicaba, 2007.

GONDIM, A.R.O.; PUIATTI, M.; VENTRELLA, M.C.; CECON, P.R. Plasticidade anatômica da folha de taro cultivado sob diferentes condições de sombreamento. Bragantia, Campinas, v.67, n.4, p.1037-1045, 2008.

GRASSI, G.; MEIR, P.; CROMER, R.; TOMPKINS, D.; JARVIS, P.G. Photosynthetic parameters in seedlings of Eucalyptus grandis as affected by rate of nitrogen supply. Plant Cell and Environment, Oxford, n.25, p.1677-1688, 2002. 
GRECHI, I.; VIVIN, P.H.; HILBERT, G.; MILIN, S.; ROBERT, T.; GAUDILLÈRE, J. P. Effect of light and nitrogen supply on internal C:N balance and control of root-to-shoot biomass allocation in grapevine. Environmental Experimental Botany, Elmsford, v.59, p. 139-149, 2007.

GRINDLAY, D.J.C. Towards in explanation of crop nitrogen demand based on the optimization of leaf nitrogen per unit leaf area. Journal of Agricultural Science, Cambridge, v.128, p.377-396, 1997.

HENRIQUES, A.R.P.; MARCELIS, L.F. M. Regulation of growth at steady - state nitrogen nutrition in Lettuce (Lactuca sativa L.): Interactive effects of nitrogen and irradiance. Annals of Botany, London, v. 86, p. 1.073-1.080, 2000.

HIROSE, T.; BAZZAZ, F. A. Trade-off between ligth- and nitrogen - use efficiency in canopy photosynthesis. Annals of Botany, London, v.82, p.195-202, 1998.

LICHTENTHALER, H.K. Chlorophylls and carotenoids: pigments of photosynthetic biomembranes. In: COLOWICK, S.P.; KAPLAN, N.O. Methods enzymology. New York: Academic, 1987. p.350-382.

LIMA JÚNIOR, E.C.; ALVARENGA, A.A.; CASTRO, E.M.; VIEIRA, C.V.; BARBOSA, J.P.R.A. D. Aspectos fisioanatômicos de plantas jovens de Cupania vernalis CAMB. submetidas a diferentes níveis de sombreamento. Revista Árvore,Viçosa, MG, v.30, n.1, p. 33-41, 2006.

MELETTI, M.M.; MAIA, M.L.Maracujá: produção e comercialização.Campinas: Instituto Agronômico, 1999. 64p. (BoletimTécnico,181).

MOHOTTI, A.J.; LAWLOR, D.W. Diurnal variation of photosynthesis and photoinhibition in tea: effects of irradiance and nitrogen supply during growth in the field. Journal Experimental Botany, Oxford, v.53, n.367, p.313-322, 2002.

NASCIMENTO, E.A.; OLIVEIRA, L.E. M.; CASTRO, E.M.; FILHO, N. D.; MESQUITA, A.C.; VIEIRA, C.V. Alterações morfofisiológicas em folhas de cafeeiro (Coffea arabica L.) consorciado com seringueira (Hevea brasiliensis Muell. Arg.). Ciência Rural, Santa Maria, v.36, n.3, p.852-857, 2006.
NATALE, W.; PRADO, R. M.; ALMEIDA, E. V.; BARBOSA, J.C. Adubação nitrogenada e potássica no estado nutricional de mudas de maracujazeiro amarelo. Acta Scientiarum Agronomy, Maringá, v.28, n.2, p.187-192, 2006.

OLIVEIRA, C.R.M.; BARBOSA, J.P.R.A.D.; SOARES, A.M.; OLIVEIRA, L.E.M.; MACEDO, R.L.G. Trocas gasosas de cafeeiros (Coffea arabica L.) e seringueiras (Hevea brasiliensis Muell. Arg.) em diferentes sistemas de cultivo na região de Lavras-MG. Revista Árvore, Viçosa, MG, v.30, n.2, p.197-206, 2006.

PIRES, M.V.; ALMEIDA, A.A. ; FIGUEIREDO, A.L.; GOMES, F.P.; SOUZA, M.M. Photosynthetic characteristics of ornamental passion flowers grown under different light intensities. Photosynthetica, Prague, v.49, n.4, p.593-602, 2011.

POMPEU, R.C.F.F.; CÂNDIDO, M.J.D.; LOPES, M..N.; GOMES, F.H.T.; LACERDA, C. F.; AQUINO, B.F.; MAGALHÃES, J.A. Características morfofisiológicas do capim-aruana sob diferentes doses de nitrogênio. Revista Brasileira de Saúde e Produção Animal, Salvador, v.11, n.4, p.11871210, 2010.

RAMALHO, I.C.; CAMPOS, P.S.; QUARTIN, V.L.; SILVA, M.I.; NUNES, M.A. High irradiance impairments on photosynthetic eletron transport, ribulose -1,5 -bisphosphate carboxylase, oxigenase and $\mathrm{N}$ assimilation as a function of $\mathrm{N}$ availability in Coffea arabica L. Journal Plant Physiology,

SABBI, L.B.C.; ANGELO, A.C.; BOEGER, M. R. Influência da luminosidade nos aspectos morfoanatômicos e fisiológicos de folhas de Schinus terebinthifolius Raddi (Anacardiaceae) implantadas em duas áreas com diferentes graus de sucessão, nas margens do reservatório Iraí, Paraná, Brasil. IHERINGIA, Série Botânica. Porto Alegre, v. 65, n.2, p.171-181, 2010.

SCALON, S.P.Q.; MUSSURY, R.M.; RIGONI, M.R.; FILHO, H.S. Crescimento inicial de mudas de Bombacopsis glabra (Pasq.) A. Robyns sob condições de sombreamento. Revista Árvore, Viçosa,MG, v.27, n.6, p.753-758, 2003. 
SILVA, M.L.S.; VIANA, A.E.S.; SÃO JOSÉ, A.R.; AMARAL, C.L.F.; MATSUMOTO, S. N.; PELACANI, C.R. Desenvolvimento de mudas de maracujazeiro (Passiflora edulis Sims f. flavicarpa Deg.) sob diferentes níveis de sombreamento. Acta Scientiarum Agronomy, Maringá, v.28, n.4, p.513521, 2006.

SMITH, H; WHITELAM, G. C The shade avoidance syndrome: multiple responses mediated by multiple phytochromes. Plant Cell Environment, Oxford, v.20, p.840-844, 1997.
SOUZA, H. A.; MENDONÇA, V.; ABREU, N.A.A.; TEXEIRA, G. T.; GURGEL, R. L. S.; RAMOS, J.D. Adubação nitrogenada e substrato na produção de mudas de maracujazeiro-doce. Ciência e Agrotecnologia, Lavras, v.31, n.3, p.599-604, 2007. ${ }^{1}$

ZANELLA, F.; SONCELA, R.; LIMA, A.L.S. Formação de mudas de maracujazeiro- "amarelo" sob níveis de sombreamento em Ji- Paraná-RO. Ciência e Agrotecnologia, Lavras, v. 30, n.5, p.880-884, 2006. 